\title{
Properties of Malaysian Solid Coco-Lumber
}

\author{
${ }^{1}$ Khairul, M., ${ }^{1}$ Abdul Hamid, S., ${ }^{1}$ Izran, K., ${ }^{1}$ Mohd Jamil, A.W., ${ }^{1}$ Mohamad Omar, M.K., \\ ${ }^{1}$ Khairul, A., ${ }^{1}$ Hamdan, H., ${ }^{1}$ Yanti, A.K., ${ }^{1}$ Emlee, M.T., ${ }^{2}$ Nasarudin, M.I., ${ }^{3}$ Razali, A.K., \\ ${ }^{3}$ Azrena, A.K. and ${ }^{3}$ Nurfaizah, A.L.
}

\begin{abstract}
Solid coco-lumber is relatively a new raw material in Malaysia's furniture industry. However, different situations can be seen in the Philippines and Indonesia as they are actively producing and marketing coconut wood-based products. In this study, the physical and mechanical properties such as moisture content, basic density, Modulus of Rupture (MOR), Modulus of Elasticity (MOE), shear stress, compression parallel to the grain, thickness swelling and water absorption properties of Malaysian solid coco-lumber were determined. The solid coco-lumber was divided into inner and outer parts and were tested under two different conditions i.e. green and air-dry conditions. The study showed that the physical and mechanical properties of the air-dried outer part of the solid coco-lumber were $50 \%$ higher compared to the inner part under both conditions. The results proved that the properties of coconut wood tested are very useful to the emerging coco-lumber based furniture industry in Malaysia.
\end{abstract}

Keywords: Coconut, potential, physical and mechanical, furniture.

${ }^{1}$ Forest Research Institute Malaysia, Kepong, 52109, Selangor, Malaysia.

(khairulm@ frim.gov.my)

${ }^{2}$ Furniture Industry Technology Center, Off KM 13, Jln. Batu Caves, 68100 Batu Caves, Kuala Lumpur, Malaysia.

${ }^{3}$ Universiti Teknologi Mara (UiTM), 40450 Shah Alam, Selangor, Malaysia. 


\section{Introduction}

The coconut palm (cocos nucifera) is one of the amazing trees because almost $90 \%$ of this tree can give many astonishing benefits to human beings. All parts of the tree can be utilized to other products. With this advantage, the coconut tree is also called as 'green' tree. This plant is used in various industries such as soap, cosmetics, rope, lumber, fuel, fertilizer, charcoal filters, and a host of domestic products that are woven from the leaves (Vogel, 2005). The coconut palm has been recognized as an economically important tree since 4000 years ago (Anon, 2009a). Coconut needs full exposure to the sun to achieve constant growth and to be in a good condition.

Asia is recorded as the largest coconut producer. The region covers about $85 \%$ of the whole world coconut production (Ohler, 1984). Philippines is the largest exporter of coconut products in which $80 \%$ of its production are exported and $20 \%$ are consumed domestically (Faustino, 2006). Coconut wood has proven to be comparable to conventional wood in terms of durability, sturdiness, versatility, good appearance and low in price. The cost of producing coconut wood as a construction material is half than that of conventional wood (FAO, 2009). Coco-lumber is commercially useful only after 50 years of age, when the coconut yields begin to decrease. Coconut tree starts to produce fruits at the age of 6 years and the production decreases when the tree achieves 60 years of age (Anon, 2009c).

\section{Status in Malaysia}

In Malaysia, coco-lumber appears to be a less-known or given less-attention as a raw material, when compared with other countries such as India, Philippines and Indonesia. These countries have worked on this material and have developed markets for its continuous utilization in the last 45 years (Anon, 2008). According to Sivapragasam contribution from the coconut industry to the overall economy of Malaysia is very small and in 2006 it was $0.08 \%$. The utilization of coconut is mainly for vegetable oil, beginning in 1960. However the production of coconut oil decreases due to the competition of other vegetable oils such as soybean, palm oil, palm kernel oil and rapeseed (Sivapragasam, 2008). Malaysians are more interested to use coconut as a source of foods. In Malaysia, there are 17 companies produce coconut milk, coconut cream, low fat desiccated coconut, dairy creamer and desiccated coconut. Only 4 companies are producing coir fibre products, activated carbon, charcoal, virgin coconut oil, and coconut lumber (plywood) (MOA, 2008).

Table 1. The total area of coconut planted in Malaysia

\begin{tabular}{|c|c|}
\hline Year & $\begin{array}{c}\text { Total area under coconut } \\
\text { (ha) }\end{array}$ \\
\hline 2001 & 151,004 \\
2002 & 136,915 \\
2003 & 131,709 \\
2004 & 143,089 \\
2005 & 130,481 \\
2006 & 114,949 \\
2007 & 109,185 \\
$2010^{\mathrm{e}}$ & 80,000 \\
\hline
\end{tabular}

Source: Department of Agriculture (DOA), Malaysia (estimated figures).

This research was done with the intention to reveal the hidden potential of coco-lumber, in terms of its physical and mechanical properties, with furniture industry as the targeted industry. These research findings are expected to change the view and acceptance level of the furniture manufacturers on this industrial crop, hence, helping the country to generate additional income which of course will give benefits to both the furniture manufacturers and coconut growers in the community.

\section{Materials and methods}

The main objective of this study is to determine the physical and mechanical properties of Malaysian solid coco-lumber (Cocos nucifera) which were obtained from a 
coconut plantation in Bagan Datoh, Hutan Melintang, Perak, Malaysia. The stems (3 trees) were cut into 2 meters (billets) according to its portions i.e. bottom, middle and top (Figure 1).

Figure 1. The portions and their targeted utilizations

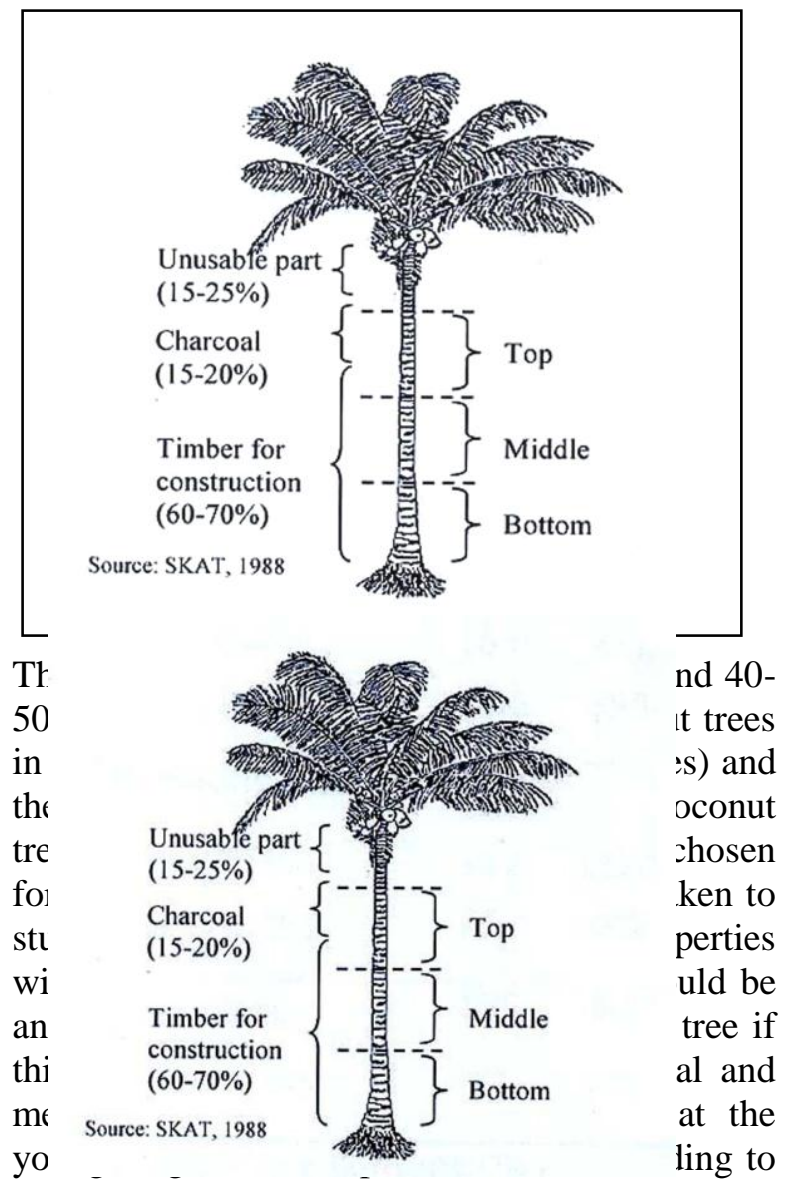

the ASTM D5536-97 (2004) (Figure 2) prior to testing in accordance with BS 373:1957 (methods of testing small clear specimen of timber). While for the thickness swelling and water absorption test, we used in-house method (Ref: EN 317:1993). The solid coco-lumber was divided into outer and inner part. The testing was conducted under two

Figure 2. The Cutting patterns of the trunk conditions; i.e. green and air-dry conditions. The mechanical test was performed by using 10KN Shimadzu Universal Testing Machine (Model 4204) available in Wood Composite Testing Laboratory of Forest Research Institute Malaysia (FRIM). The physical tests involved in this research were moisture content, density, specific gravity, thickness swelling and shrinkage determinations, where as the mechanical tests were static bending [modulus of rupture (MOR), modulus of elasticity (MOE)], compression stress and shear strength. The means of the test results, then, were analyzed using t-test.

\section{Results and discussion}

\section{Wood Properties}

The basic properties of the wood are presented in Table 2 and compared with previous study. The results are the means for the whole stem which are a combination of three different portions of the coconut stem, i.e. bottom, middle and top. While in Table 4, it shows the properties of each different portion of coconut stem namely bottom, middle and top also compared with previous study done by Killmann. Each grade has different properties which is compatible to be used for different applications. There are unique characteristics of these coco-lumber grades with large variations of colour, grain and shade which

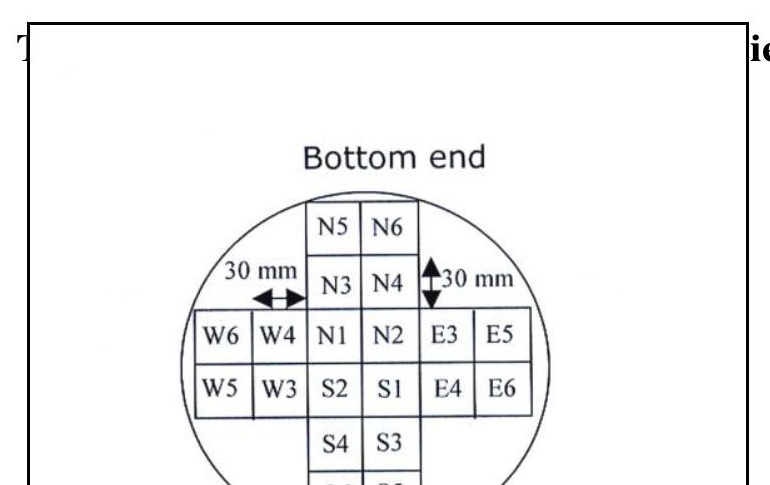

ies solid coconut: green and air-dry samples with 


\begin{tabular}{|l|ccccccc|}
\hline Wood Sample & MC & WD & SG & MOR & MOE & CS & SS \\
\hline Green & & & & & & & \\
Outer & 116 & 590 & 0.59 & $69.8^{\mathrm{k}}$ & $10296^{\mathrm{m}}$ & $37.1^{\mathrm{g}}$ & $4.6^{\mathrm{c}}$ \\
Inner & 242 & 327 & 0.33 & $24.6^{\mathrm{j}}$ & $7738^{\mathrm{o}}$ & $12.6^{\mathrm{e}}$ & $3.8^{\mathrm{a}}$ \\
\hline Air-dry & & & & & & & \\
Outer & 16.0 & 751 & 0.65 & $85.4^{1}$ & $9576^{\mathrm{n}}$ & $48.7^{\mathrm{h}}$ & $12.0^{\mathrm{d}}$ \\
Inner & 14.5 & 390 & 0.34 & $28.4^{\mathrm{i}}$ & $3667^{\mathrm{p}}$ & $16.2^{\mathrm{f}}$ & $4.8^{\mathrm{b}}$ \\
\hline Previous study* & & & & & & & \\
${ }^{1}$ Green & 162 & 1120 & 0.43 & 29 & 4500 & 21.2 & 5.1 \\
${ }^{1}$ Air-dry & 19.2 & 495 & 0.43 & 36 & 5300 & 23.9 & 5.7 \\
\hline${ }^{2}$ Green & 135 & n.a & n.a & 55 & 6946 & 31.6 & 6.6 \\
${ }^{2}$ Air-dry & 12 & n.a & n.a & 67 & 7388 & 38.0 & 10.5 \\
\hline
\end{tabular}

MC: Moisture content (\%)

WD: Wood density $\left(\mathrm{kg} / \mathrm{m}^{3}\right)$

SG: Specific gravity
MOE: Modulus of elasticity $\left(\mathrm{N} / \mathrm{mm}^{2}\right)$

CS: Compression stress $\left(\mathrm{N} / \mathrm{mm}^{2}\right)$

SS: Shear strength $\left(\mathrm{N} / \mathrm{mm}^{2}\right)$

MOR: Modulus of rupture $\left(\mathrm{N} / \mathrm{mm}^{2}\right)$

${ }^{1}$ Means within a row followed by the same alphabets are not significantly different at $p \leq 0.05$

*Source: ${ }^{1}$ The strength properties of some Malaysian timbers (pg. 56), 1979, raw material from

Telok Anson. ${ }^{2}$ Killmann W., How to Process Coconut Palm Wood, 1988.

Table 3. Thickness swelling and water absorption

\begin{tabular}{|l|ccc|}
\hline \multicolumn{1}{|c|}{ WS } & WD & TS $(\%) \pm$ S.D & WA (\%) \pm S.D \\
\hline Bottom (Inner) & 393.84 & $2.14 \pm 0.52^{\mathrm{e}}$ & $45.44 \pm 7.77^{\mathrm{k}}$ \\
Middle (Inner) & 445.30 & $2.12 \pm 0.64^{\mathrm{c}}$ & $57.29 \pm 19.77^{\mathrm{i}}$ \\
Upper (Inner) & 353.08 & $7.14 \pm 4.53^{\mathrm{a}}$ & $92.31 \pm 43.10^{\mathrm{g}}$ \\
Bottom (Outer) & 775.39 & $2.66 \pm 0.75^{\mathrm{f}}$ & $18.84 \pm 5.23^{1}$ \\
Middle (Outer) & 659.71 & $2.42 \pm 0.90^{\mathrm{d}}$ & $24.61 \pm 5.88^{\mathrm{j}}$ \\
Upper (Outer) & 607.18 & $2.09 \pm 0.69^{\mathrm{b}}$ & $33.14 \pm 4.43^{\mathrm{h}}$ \\
\hline
\end{tabular}

WS: Wood sample WD: Wood density

TS: Thickness swelling WA: Water absorption

SD: Standard deviation

${ }^{1}$ Means within a row followed by the same alphabets are not significantly different at $p \leq 0.05$

enable a wider range of textural selection. The

trunk is very tough and hard due to the amount of silica available in the trunk and the structure of its fibres (Vogler, 1986).
The portions, the parts and the test conditions were also found to influence the performance on the mechanical and physical properties of the trunk (Table 4). The results 
(Table 4) of the mechanical tests conducted under the two different conditions showed that the strength of the outer part was superior to the inner part and the results of the air-dry trunk was recorded better than the green except for the MOE. The lower performance of the green samples (except the MOE) might be caused by the presence of moisture (based on the average MC values for both parts; $116 \%$ for the outer and $242 \%$ for the inner) in the green samples. The moisture caused the samples present too soft and more elastic than that of the air-dry. This can be proven by looking at the value of MOE for both conditions. It was also expected that the results were influenced by the characteristics of the inner part itself. The inner core is very weak and low density wood (Vogler, 1986). The inner part's thickness swelling and water absorption values were found between 2.14 to $7.14 \%$ and 45.44 to 92.31\% whereas; the outer's were between 2.09 to $2.66 \%$ and 18.84 to $33.14 \%$.

Based on the data analysis done, there was significant difference between parts and portions (green vs. air-dry). Based on the comparison of mean values between parts, it was found that the thickness swelling and water absorption of the inner part were higher than the outer part. This might be another answer to the low strength of the inner part compared to the outer part. It was recorded that the upper part possesses the highest thickness swelling and water absorption, when a comparison of the means was made between portions. However, even though the inner core possesses low strength, it can be used to produce paneling or mass production furniture such as school desks, table legs and bed posts (Anon, 2009). It is expected that impregnating resin into the inner coco-lumber will increase the mechanical and physical properties similar with oil palm lumber (Abdul Khalil et. al. 2009).

The results obtained from this study slightly contradicted with the previous study which is presented in the table (Table 2). The previous studies showed that the presence of moisture did not improve the modulus of elasticity of the trunk. However, both studies have the same results on the adverse effects of $\mathrm{MC}$ to the MOR, compression stress and shear strength. Those parameters decreased as the MC increased.

MC seems to be a burden that needs to be handled carefully, in order to make the promotion on the usage of coconut trunk successful. High MC makes the use of trunk seems unpopular compared with other parts of the plants. The MC increases the weight of the trunk and makes trunk transferring process from plantation area to processing factory becomes very costly (Vougler, 1986). Each portion of a coconut trunk presents different value of density. The density of the top portion is usually less than $200 \mathrm{~kg} / \mathrm{m}^{3}$. The middle portion's is $200-400 \mathrm{~kg} / \mathrm{m}^{3}$. These two portions are used for biomass fuel. The suitable portion for sawn timber is the bottom, in which the density is normally around $400-1000 \mathrm{~kg} / \mathrm{m}^{3}$ (Anon, 2009; Vogler, 1986).

\section{Conclusions}

Based on the study, it was proven that the coconut trunk is suitable for many purposes due to its wide variations of densities as cited by previous studies in many publications. The high moisture content available in the trunk causes many undesirable problems to its strength. Therefore, effective drying prior to the utilization of the trunk is important to extend its usage. However from the positive view, the moisture may also help to increase the elasticity of the trunk. This might be a good explanation why coconut trunk is frequently used by the villagers to build bridges. Further researches can be conducted to accelerate the promotion of coconut trunks to the

Table 4. Means of the basic properties solid coco-lumber for different portions (bottom, middle and top)

\begin{tabular}{|l|lllllll|}
\hline Wood Sample & MC & WD & SG & MOR & MOE & CS & SS \\
\hline Green & & & & & & & \\
\hline
\end{tabular}




\begin{tabular}{|c|c|c|c|c|c|c|c|}
\hline Bottom & 107.2 & 1138.9 & 0.59 & 66.45 & 9383 & 36.78 & 29.53 \\
\hline Middle & 84.3 & 1166.9 & 0.65 & 83.42 & 10131 & 44.31 & 71.85 \\
\hline Top & 140.9 & 1138.7 & 0.56 & 71.21 & 12222 & 35.37 & 39.05 \\
\hline Bottom & 245.7 & 1061.9 & 0.32 & 22.46 & n.a & 13.19 & 4.78 \\
\hline Middle & 182.5 & 1066.1 & 0.39 & 37.14 & 7738 & 18.63 & 59.08 \\
\hline Top & 297.3 & 1042.2 & 0.27 & 14.31 & n.a & 6.10 & 17.13 \\
\hline \multicolumn{8}{|l|}{ Air-dry } \\
\hline Bottom & 18.4 & 756.9 & 0.65 & 79.93 & 9224 & 48.65 & 11.3 \\
\hline Middle & 14.1 & 779.0 & 0.68 & 95.23 & 10355 & 51.35 & 13.8 \\
\hline Top & 14.1 & 710.1 & 0.62 & 84.06 & 9308 & 46.02 & 11.4 \\
\hline Bottom & 14.9 & 328.7 & 0.29 & 20.02 & 2176 & 13.48 & 3.3 \\
\hline Middle & 14.0 & 452.5 & 0.40 & 36.72 & 4043 & 23.40 & 6.3 \\
\hline Top & n.a & n.a & n.a & n.a & n.a & n.a & n.a \\
\hline \multicolumn{8}{|l|}{ "Green } \\
\hline Bottom & 57 & $600+$ & n.a & 86 & 10857 & 49 & 10 \\
\hline Middle & 107 & $400-599$ & n.a & 53 & 6880 & 31 & 6 \\
\hline Top & 240 & $250-399$ & n.a & 26 & 3100 & 15 & 4 \\
\hline \multicolumn{8}{|l|}{${ }^{*}$ Air-dry } \\
\hline Bottom & 12 & $600+$ & n.a & 104 & 11414 & 57 & 13 \\
\hline Middle & 12 & $400-599$ & n.a & 63 & 7116 & 38 & 8 \\
\hline Top & 12 & $250-399$ & n.a & 33 & 3633 & 19 & n.a \\
\hline
\end{tabular}

*Source: Killmann W., How to Process Coconut Palm Wood, 1988.

MC: Moisture content (\%) MOE: Modulus of elasticity $\left(\mathrm{N} / \mathrm{mm}^{2}\right)$

WD: Wood density $\left(\mathrm{kg} / \mathrm{m}^{3}\right) \quad$ CS: Compression stress $\left(\mathrm{N} / \mathrm{mm}^{2}\right)$

SG: Specific gravity SS: Shear strength $\left(\mathrm{N} / \mathrm{mm}^{2}\right)$

MOR: Modulus of rupture $\left(\mathrm{N} / \mathrm{mm}^{2}\right)$

n.a (top - inner air-dry) = samples destroy due to fungus attack and twisted.

Communities in Malaysia. It may be treated with

fire retardants to produce fire-retardant coconut lumber to enhance its toughness to fire or by treating it with wood preservatives to enhance its durability to prevent it from being attacked by its natural enemies. With its versatile characteristics: adorable strength, good elasticity, coconut could be a good substitute for forest trees as an input for the wood-based industries.

\section{References}

Abdul Khalil et. al. 2009. Mechanical and physical properties of resin impregnated 
oil palm trunk core lumber. Polymer Composites-Wiley InterScience (publish online).

Anonymous. 2008. Prices of major products traded in the global markets, The cocommunity, Vol XXXVIII (9).

Anonymous. 2009. Coconut Wood, available online: http://www.coconut-wood.com/ usingcoconut.html. [Accessed on July 2009]

Anonymous. 2009a. Coconut Palm Tree: Cocos nucifera, available online: http://coconutpalmtree.net/. [Accessed on August 2009]

Anonymous. 2009b. Coconut Tree, available online: http://www.desert-tropicals.com/ Plants/Arecaceae/Cocos nucifera.html.

[Accessed on August 2009]

Anonymous. 2009c. Uses of Coconut Tree, available online: http://hubpages.com/ hub/Uses-of-Coconut-Trees, [Accessed on August 2009]

ASTM D 5536 - 94:2006. Standard Practice for Sampling Forest Trees for Determination of Clear Wood Properties. BS 373:1957. Methods of testing small clear specimens of timber. Standard status reconfirmed on November 2008.

BS 373:1957. Methods of testing small clear specimens of timber. Standard status reconfirmed on November 2008.

FAO, 2009. Economics of Coconut Wood Utilization, Available online: http://www.fao.org/docrep/w7731e/w7731 e05.htm\#TopOfPage, [Accessed on June 2009]

Vogel, R.M. 2005. The tree of life, Food for thought, available online: http://www.foodreference.com/html/acoconut-tree-life.html. [Accessed on May 2009]

Vogler, J. 1986. Understanding non-fuel uses of wood wastes, Technical Paper \#47 VITA, available online: http://sleekfreak.ath.cx:81/3wdev/
Faustino, J. 2006. Facing the challenges of the Philippine coconut industry: The lifeblood of 3.4 million coconut farmers and farm workers, Coconut Industry reformed movement inc.: 1-74.

Killmann W. 1988. How to Process Coconut Palm Wood. Vieweg Verlag. Braunschwerg. $76 \mathrm{p}$.

Lee YH. et al. 1979. The strength properties of some Malaysian timbers. Forestry Department Peninsular Malaysia, 56.

Md Yusoff, I. 2009. Market potential for cocolumber products, paper presented at National coconut conference 2009, Damai Laut, Perak, Malaysia, 28-30 July 2009.

MOA, 2001. National Coconut Development Plant (2001-2010).

MOA, 2008. List of Malaysian companies and their coconut products.

Ohler, J.G. 1984. Coconut, tree of life, FAO Plant Production and Protection Paper, No. 57, 395-436.

Roland Stulz and Kiran Mukerji, 1988. Appropriate Building Materials: a Catalogue of Potential Solutions (SKAT).

Sivapragasam, A. 2008. Coconut in Malaysia current developments and potential for revitalization, paper presented at the $2^{\text {nd }}$ International Plantation Industry Conference and Exhibition (IPICEX2008), Shah Alam, Malaysia, 1821 September 2008.

VITAHTML/SUBLEV/EN1/WOODWAS

T.HTM. [Accessed on July 2009]. ISBN: 0-86619-261-1 
Cord 2009, 25 (2) 